\title{
Flatfoot Prevalence in Riyadh City Saudi Arabia And Its Association with Obesity, Using Three Footprint Indices; Clark's Angle, Chippaux-Smirak Index, and Staheli Index
}

\author{
Abdulaziz Almaawi*, Nawaf Alotaibi, Mohammed Alsubaie, Nouf Altwaijri, Khalid Alduraibi, Waleed Awwad \\ and Abdulrahman Algarni
}

Department of Orthopedic surgery, College of Medicine, king Saud University, Saudi Arabia

Submission: November 13, 2019; Published: November 27, 2019

*Corresponding author: DR. Abdulaziz Almaaw, Department of Orthopedic surgery, College of Medicine, king Saud University, Saudi Arabia

\begin{abstract}
Background and Purpose: Flatfoot is a condition in which the foot is characterized by a flat medial longitudinal arch either congenitally or acquired. The prevalence of flatfoot varies worldwide. Our aims in this study were to estimate the prevalence of adult flatfoot in Riyadh city, Saudi Arabia. And to evaluate the relationship between adult flatfoot and the Body Mass Index (BMI).

Methods and Study design: Initially the demographic data of the participants such as Name, age, Gender, Height, Weight, Nationality were obtained. Foot examination was done by a podiatrist using a podoscope. We used three types of footprint parameters to determine the foot arch; Clark's angle, Chippaux-Smirak index, and Staheli index indices were calculated twice by the same person.

Results: This study included 533 (218 males, and 315 females) with mean age 37 years (SD 11.26). Most of the participants were Saudi 417 (78.2\%), while 116 (21.8\%) were non-Saudi. The prevalence of flatfoot is different according to the footprint parameters. We observed that some participants have different types of the arch between right and left feet, either a pair of normal and flat arches, normal and high arches or flat and high arches. The diagnosis of flatfoot increased with high BMI where all footprint parameters showed a significant correlation (P-value $<0.05$ ) between high BMI and flatfoot.
\end{abstract}

Conclusion: As seen in our results, Flat foot is common in our community. Flatfoot can result in pain and disability if left uncorrected. As healthcare providers we should raise the level of awareness of the population that the incidence of the flat foot and its complications increase with obesity, which may decrease the quality of life. The authors recommended to establish a new method to diagnose flatfoot that gives us an accurate measure.

Keywords: Flat foot; Obesity; Prevalence; Saudi Arabia

Abbreviations: CA: Clark's Angle; SI: Staheli Index; CSI: Chippaux-Smirak Index

\section{Introduction}

The foot is a biomechanical structure works perfectively in the presences of healthy bones, muscles, and ligaments. Threefoot arches support the function of the foot, and the medial longitudinal arch is considered the most important clinically [1]. Theses arches help the foot in the distribution of the body weight while standing, support the foot during the gait cycle and provide a proper adjustment on different surfaces. Any disorder affecting theses arches will interfere with the normal function of different muscle groups and joints at varying levels of the lower extremity and low back [2]. Flatfoot is a condition in which the foot is characterized by a flat medial longitudinal arch either congenitally or acquired [3]. There are two types of flatfoot flexible and rigid, in flexible flatfoot; the medial longitudinal arch can be observed when the person in a non-weight bearing position, but it disappears with weight-bearing posture. While in rigid type the medial longitudinal arch cannot be seen even with non-weight bearing position [4].

Flatfoot has a number of complications if left untreated. Worsening pain started along the aspect of the posterior tibial tendon, and structural foot deformities such as forefoot abduction and hindfoot valgus are possible complications seen in flatfoot patients [5]. Flatfoot is mainly a clinical diagnosis. However, radiological studies and a podoscope examination can also diagnose flatfoot [6-8]. The prevalence of flatfoot 
varies worldwide. Our aims in this study were to estimate the prevalence of adult flatfoot in Saudi Arabia. And to evaluate the relationship between adult flatfoot and the Body Mass Index (BMI).

\section{Methodology}

This cross-sectional study was conducted in the Department of Orthopedic, College of Medicine, King Saud University, Riyadh, Saudi Arabia, during the period from October 2018 to April 2019. We followed a convenience sampling method. We organized a flatfoot awareness campaign at one of the biggest malls in Riyadh city the capital of Saudi Arabia. Through the campaign we asked people to be a participant in our study as one booth of the campaign was foot examination. We included anyone who is 18 years old or above and does not have neuromuscular disorders, previous fracture, surgical treatment, or other causes of pathological flatfoot.

Initially the demographic data of the participants such as Name, age, Gender, Height, Weight, Nationality were obtained. Foot examination was done by a podiatrist using a podoscope. We scanned the both feet, and all pictures were saved. We used three types of footprints parameters to determine the foot arch; Clark's angle, Chippaux-Smirak index, and Staheli index indices Results were calculated twice by the same person. We used a photoshop CS5 software to measure the footprint arching parameters [9]. Clark's angle as defined by Clark [10] is the angle between two lines; first line connects the medial aspect of the first metatarsal bone and the medial side of the heal, where the second line that crosses a line at first metatarsal bone to the acme of the medial longitudinal arch concavity. Clark's angle considered to be normal if the values are between $42^{\circ}-54^{\circ}$, flat $\operatorname{arch}<41^{\circ}$, and high $\operatorname{arch}>55^{\circ}[11]$.

Chippaux-Smirak index is calculated by dividing the narrowest distance of the midfoot over the widest distance of the forefoot. Normal arch if the ratio is between $(25 \%-45 \%)$, flat $\operatorname{arch}>45 \%$, high $\operatorname{arch}<25 \%$. Staheli index is the ratio between the minimal distance of midfoot and maximal distance of hindfoot. The ratio is categorized into; high arch (0.1-0.4), normal arch (0.5-0.7) and flat arch (0.8-1.2) [12]. Data were analyzed by using Statistical Package for Social Studies (SPSS 22; IBM Corp., New York, NY, USA). Continuous variables were expressed as a mean \pm standard deviation, and categorical variables were expressed as percentages. Chi-Square Tests were used for continuous variables. A P-value $<0.05$ was considered statistically significant.

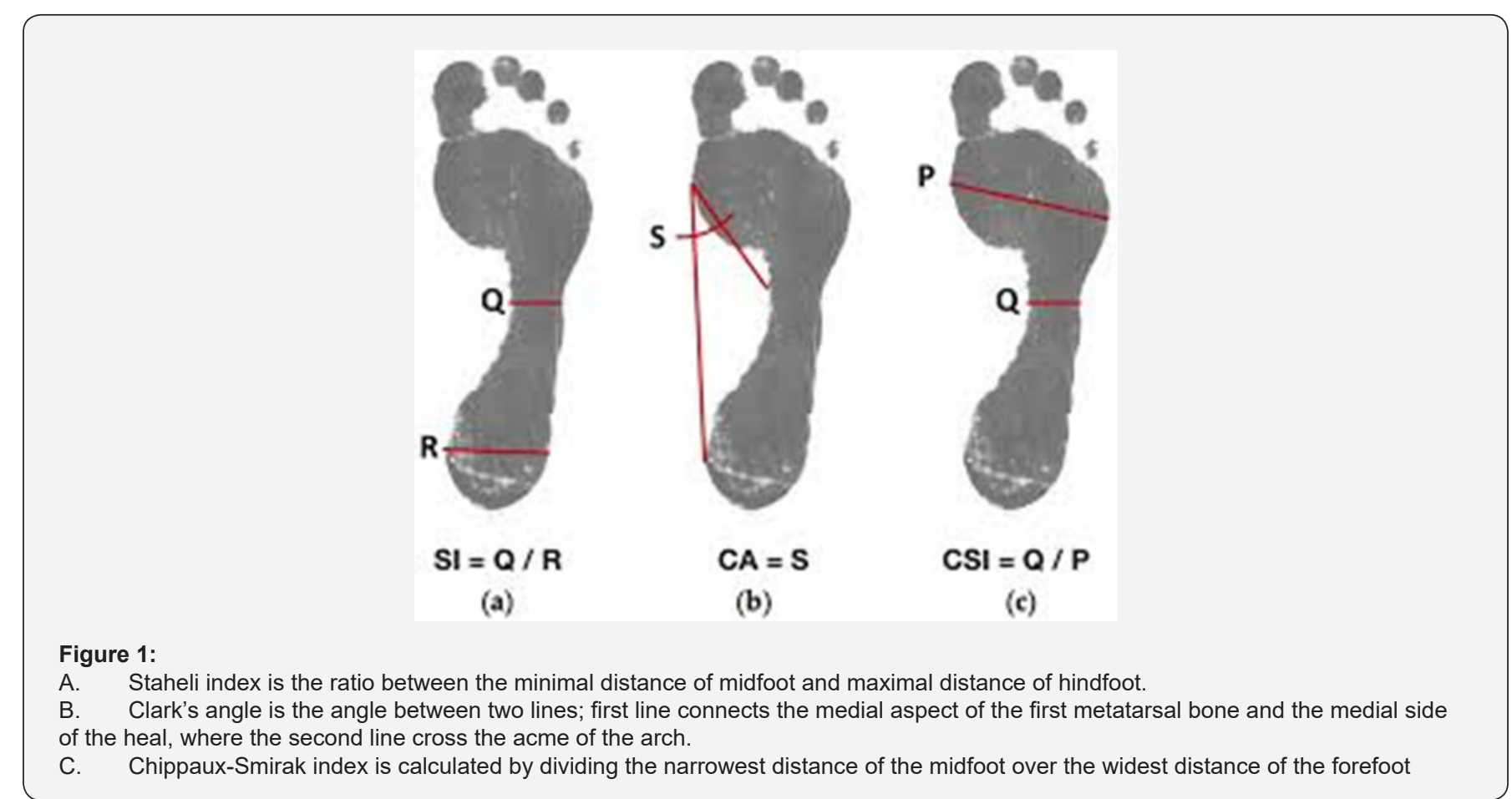

This study included 533 (218 males, and 315 females) with mean age 37 years (SD 11.26). Most of the participants were Saudi 417 (78.2\%), while 116 (21.8\%) were non-Saudi. There were four categories of BMI; underweight (BMI < 18.5), normal (BMI 18.5 - 24.9), overweight (BMI 25 - 29.9), and obese (BMI $\geq$ 30) (Figure 1). The foot arch was determined by three footprints parameters; Clark's angle (CA), Chippaux-Smirak index (CSI), and Staheli index (SI). The types of the foot arch according to the three-foot parameters are shown in (Table 1). The CSI and SI exhibited a significant agreement in the diagnosis of flatfoot with Kappa value $>0.8$ and $(\mathrm{P}$-value $<0.05)$. However, there was a weak agreement between Clark's angle with SI and CSI with Kappa values $<0.5$ and (P-value $<0.05$ ). 


\section{Orthopedics and Rheumatology Open Access Journal (OROAJ)}

Table 1: The types of the foot arch according to the three-foot parameters in both genders.

\begin{tabular}{|c|c|c|c|c|}
\hline & Male & Female & Total & \multirow{2}{*}{ Significance $(p<0.05)$} \\
\hline & N (\%) & N (\%) & N (\%) & \\
\hline \multicolumn{4}{|l|}{$\mathrm{R} \mathrm{CA}$} & \multirow{4}{*}{0.024} \\
\hline Normal & $111(50.9 \%)$ & $132(41.9 \%)$ & $243(45.6 \%)$ & \\
\hline High arch & $19(8.7 \%)$ & $50(15.9 \%)$ & $69(12.9 \%)$ & \\
\hline Flatfoot & $88(40.4 \%)$ & $133(42.2 \%)$ & $221(41.5 \%)$ & \\
\hline \multicolumn{4}{|l|}{ LCA } & \multirow{4}{*}{0.001} \\
\hline Normal & $123(56.4 \%)$ & $131(41.6 \%)$ & $254(47.7 \%)$ & \\
\hline High arch & $16(7.3 \%)$ & $47(14.9 \%)$ & $63(11.8 \%)$ & \\
\hline Flatfoot & $79(36.2 \%)$ & $137(43.5 \%)$ & $216(40.5 \%)$ & \\
\hline \multicolumn{4}{|l|}{ R CSI } & \multirow{4}{*}{0.093} \\
\hline Normal & $111(50.9 \%)$ & $190(60.3 \%)$ & $301(56.5 \%)$ & \\
\hline High arch & $75(34.4 \%)$ & $85(27.0 \%)$ & $160(30 \%)$ & \\
\hline Flatfoot & $32(14.7 \%)$ & $40(12.7 \%)$ & $72(13.5 \%)$ & \\
\hline \multicolumn{4}{|l|}{ L CSI } & \multirow{4}{*}{0.592} \\
\hline Normal & $118(54.1 \%)$ & $184(58.4 \%)$ & $302(56.7 \%)$ & \\
\hline High arch & 70 (32.1\%) & $94(29.8 \%)$ & $164(30.8 \%)$ & \\
\hline Flatfoot & $30(13.8 \%)$ & $37(11.7 \%)$ & $67(12.6 \%)$ & \\
\hline \multicolumn{4}{|l|}{ R SI } & \multirow{4}{*}{0.075} \\
\hline Normal & $121(55.5 \%)$ & $204(64.8 \%)$ & $325(61 \%)$ & \\
\hline High arch & $71(32.6 \%)$ & $86(27.3 \%)$ & 157 (29.5\%) & \\
\hline Flatfoot & $26(11.9 \%)$ & $25(7.9 \%)$ & $51(9.6 \%)$ & \\
\hline \multicolumn{4}{|l|}{ L SI } & \multirow{4}{*}{0.055} \\
\hline Normal & $122(56.0 \%)$ & $202(64.1 \%)$ & $324(60.8 \%)$ & \\
\hline High arch & $71(32.6 \%)$ & $93(29.5 \%)$ & $164(30.8 \%)$ & \\
\hline Flatfoot & $25(11.5 \%)$ & $20(6.3 \%)$ & $45(8.4 \%)$ & \\
\hline
\end{tabular}

CA: Clark's angle; SI: Staheli index; CSI: Chippaux-Smirak index; L: Left foot; R: Right foot

Table 2: The Measure of Agreement between Right and left feet.

\begin{tabular}{|c|c|c|c|c|c|}
\hline \multicolumn{6}{|c|}{ R CA * L CA Crosstabulation } \\
\hline & & L CA & & & \multirow{2}{*}{ Total } \\
\hline & & Flatfoot & High arch & Normal & \\
\hline \multirow[t]{3}{*}{ R CA } & Flatfoot & $202(37.9 \%)$ & $1(0.2 \%)$ & $18(3.4 \%)$ & $221(41.5 \%)$ \\
\hline & High arch & $0(0.0 \%)$ & $58(10.9 \%)$ & $11(2.1 \%)$ & 69 (12.9\%) \\
\hline & Normal & $14(2.6 \%)$ & $4(0.8 \%)$ & $225(42.2 \%)$ & $243(45.6 \%)$ \\
\hline \multicolumn{2}{|c|}{ Total } & $216(40.5 \%)$ & $63(11.8 \%)$ & $254(47.7 \%)$ & $533(100.0 \%)$ \\
\hline \multicolumn{6}{|c|}{ R CIS * L CIS Crosstabulation } \\
\hline & & \multicolumn{4}{|l|}{ L CIS } \\
\hline & & Flatfoot & High arch & Normal & Total \\
\hline \multirow{3}{*}{ R CIS } & Flatfoot & $38(7.1 \%)$ & $2(0.4 \%)$ & $32(6.0 \%)$ & $72(13.5 \%)$ \\
\hline & High arch & $2(0.4 \%)$ & $119(22.3 \%)$ & $39(7.3 \%)$ & $160(30.0 \%)$ \\
\hline & Normal & $27(5.1 \%)$ & $43(8.1 \%)$ & $231(43.3 \%)$ & $301(56.5 \%)$ \\
\hline \multicolumn{2}{|c|}{ Total } & $67(12.6 \%)$ & $164(30.8 \%)$ & $302(56.7 \%)$ & $533(100.0 \%)$ \\
\hline \multicolumn{6}{|c|}{ R SI * L SI Crosstabulation } \\
\hline & & \multicolumn{4}{|l|}{ L SI } \\
\hline & & Flatfoot & High arch & Normal & Total \\
\hline R SI & Flatfoot & 30 (5.6\%) & $0(0.0 \%)$ & $21(3.9 \%)$ & $51(9.6 \%)$ \\
\hline
\end{tabular}




\section{Orthopedics and Rheumatology Open Access Journal (OROAJ)}

\begin{tabular}{|c|c|c|c|c|c|}
\hline & High arch & $1(0.2 \%)$ & $116(21.8 \%)$ & $40(7.5 \%)$ & $157(29.5 \%)$ \\
\cline { 2 - 7 } & Normal & $14(2.6 \%)$ & $48(9.0 \%)$ & $263(49.3 \%)$ & $325(61.0 \%)$ \\
\hline Total & & $45(8.4 \%)$ & $164(30.8 \%)$ & $324(60.8 \%)$ & $533(100.0 \%)$ \\
\hline
\end{tabular}

Table 3: The significance of correlation between age categories and foot arches based on (A) Clarke index, (B) Chippaux-Smirak index, (C) Staheli index.

\begin{tabular}{|c|c|c|c|c|c|c|}
\hline \multicolumn{2}{|c|}{ A } & $<29 y$ & $29-36 y$ & $37-45 y$ & $>45 y$ & Significance $(p<0.05)$ \\
\hline Clarke index right foot & Clarke index left foot & $\begin{array}{l}36.5 \% \\
31.4 \%\end{array}$ & $\begin{array}{l}38.4 \% \\
39.1 \%\end{array}$ & $\begin{array}{l}36.9 \% \\
36.9 \%\end{array}$ & $\begin{array}{l}54.7 \% \\
55.5 \%\end{array}$ & $\begin{array}{c}0.03 \\
0.006\end{array}$ \\
\hline \multicolumn{2}{|c|}{ B } & $<29 y$ & $29-36 y$ & $37-45 y$ & $>45 \mathrm{y}$ & Significance $(p<0.05)$ \\
\hline \multicolumn{2}{|c|}{$\begin{array}{l}\text { Chippaux-Smirak index right foot Chippaux-Smirak } \\
\text { index_left foot }\end{array}$} & $\begin{array}{l}10.2 \% \\
8.8 \%\end{array}$ & $\begin{array}{l}17.4 \% \\
18.8 \%\end{array}$ & $\begin{array}{l}10.8 \% \\
10.8 \%\end{array}$ & $\begin{array}{l}15.6 \% \\
11.7 \%\end{array}$ & $\begin{array}{l}0.148 \\
0.005\end{array}$ \\
\hline \multicolumn{2}{|c|}{$\mathrm{C}$} & $<29 y$ & $29-36 y$ & $37-45 y$ & $>45 \mathrm{y}$ & Significance $(p<0.05)$ \\
\hline Staheli index right foot & Staheli index left foot & $\begin{array}{c}10.9 \% \\
8.0 \%\end{array}$ & $\begin{array}{l}13.0 \% \\
12.3 \%\end{array}$ & $\begin{array}{l}6.2 \% \\
5.4 \%\end{array}$ & $\begin{array}{l}7.8 \% \\
7.8 \%\end{array}$ & $\begin{array}{l}0.148 \\
0.016\end{array}$ \\
\hline
\end{tabular}

We observed that some participants have different types of the arch between right and left feet, either a pair of normal and flat arches, normal and high arches or flat and high arches. The measurement of agreement test was done to determine the degree of agreement between the two feet with the three different footprint parameters (Table 2). Among the foot parameters, Clark's angle had the highest degree of agreement between the right and the left feet (Kappa value $=0.850$ ) followed by Staheli index (Kappa value $=0.562$ ) followed by Chippaux-Smirak index (Kappa value $=0.523$ ). We further correlated the types of the foot arch according to the three footprint parameters; CA, CSI, and SI with the participants' age, BMI and nationalities. Table 3 shows a significant correlation between age categories and flatfoot. There is no significant difference between Saudi and non-Saudi in the prevalence of flatfoot (P-value $>0.05$ ). However, diagnosis of flatfoot increased with high BMI where all footprint parameters showed a significant correlation (P-value $<0.05$ ) between high BMI and flatfoot (Figures $2 \& 3$ ).

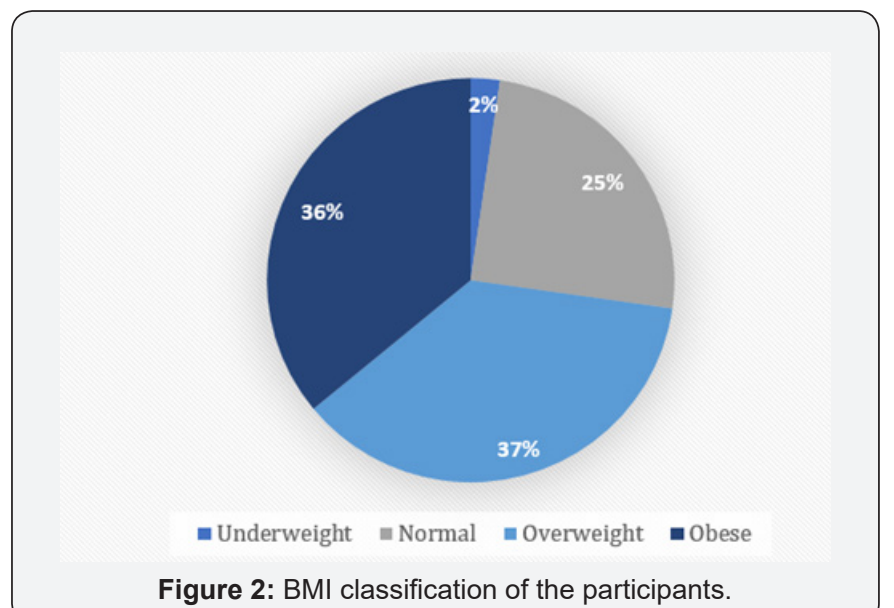

\section{Discussion}

The human feet are strong, mechanical and complex structures containing arches that protect it from injuries by acting as a spring, which absorbs shock and direct pressure during various activities [12]. To determine the type of foot arch, we used three different parameters; Clark's angle (CA), ChippauxSmirak index (CSI) and Staheli index (SI). All three parameters were considered reliable in other studies $[13,14]$. We found that the prevalence of flat foot was highest while using the CA and lowest while using SI, ergo, there were some differences in the foot arch results between the three parameters in our study, unlike other studies which found them to be similar in results $[12,15]$. Our study also found instances of unilateral high-arched feet and unilateral flat feet in some participants, much like other studies with similar results $[12,16]$. However, bilateral flat feet were found to be more common, which was attributed to the fact that congenital flat foot usually occurs bilaterally [16].

As for the agreement between those parameters, we found that the CSI and SI exhibited excellent agreement in the diagnosis of flatfoot with a Kappa value of $>0.8$ (P-value $<0.05)$ in contrast to Clarke's angle with SI and CSI, as their Kappa value was < 0.58 (P-value $<0.05$ ), which is similar to results found in the literature [17] but differed from another study which showed excellent intrarater interobserver and interrater reliability, with ICC values of $>0.880$ [18]. In addition, Clarke's Angle had the highest degree of agreement between the two feet when compared to the other footprint parameters with a Kappa value of 0.850 . One study found Clarke's angle to be highly accurate in detecting flatfoot [13].

In our results, we found that the incidence of flatfoot was higher in obese participants, suggesting a relationship between BMI and flatfoot; equivalent to other studies which showed similar results $[1,3,12,19,20]$. This could be due to added exertion forces on the arches of the feet because of weak musculature, ligaments causing the arches to collapse, significantly altering the contact surfaces between the arches and the ground [19]. Unlike other studies which show no correlation between BMI and flatfeet [21]. Furthermore, foot joint pain has been noted among higher BMI categories which likely predicts the development of foot joint stress overtime with obese participants [22,23]. Therefore, a small increase in body mass can impact plantar pressure [24]. While a modest weight reduction can have a significant reduction 
in plantar loading [25]. One study concludes that a loss of more than $2 \mathrm{~kg}$ conveys a change in functional limitation and reduced foot pain [26].

When comparing genders, we found that Clark's angle in females had higher prevalence of flat feet than males. On the other hand, CSI and SI showing insignificant higher prevalence of flatfoot in males than females. Yashika and Chougala studies reported that flatfeet are more common in males, of which they've attributed it to the foot-ware males use $[16,19]$. However, another study pointed out a higher incidence of flat feet in female school students due to the closed-toe shoes they wear which are detrimental to the development of the foot arch [3]. High-arched feet were also observed in another study to be more common in young females [1]. Other studies showed no correlation between gender and the presence of flatfeet [21].

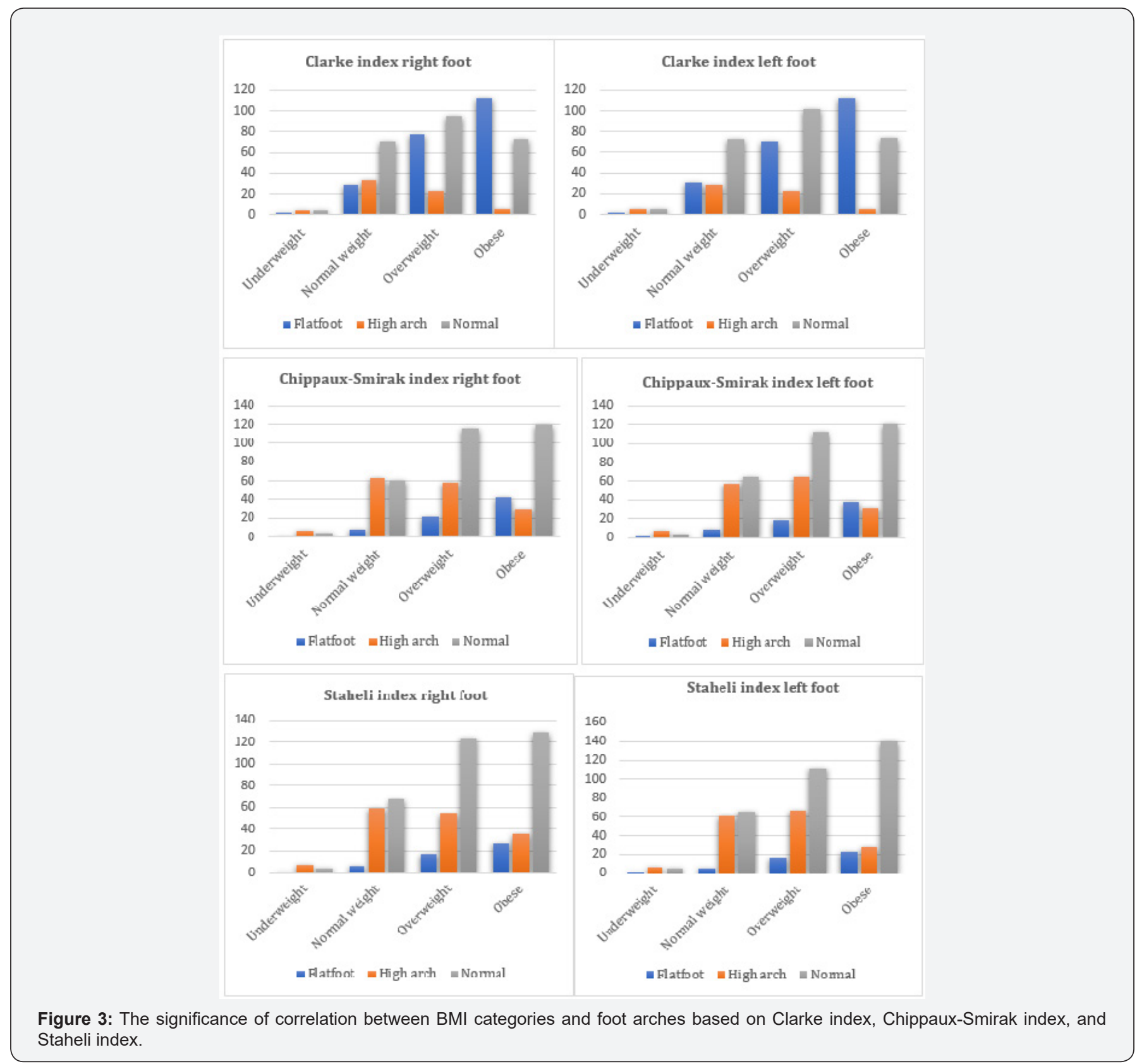

The quality of life does not seem to be affected when it comes to the presence or absence of flat foot $[13,19]$ nor does physical functioning and participation in physical activity [13]. However, some studies show that the quality of life is lower in participants with flatfeet [20]. (explain how flatfoot affected quality of life). Many of our flat-footed participants seem to experience complications related to flat feet, e.g. pain, tightness in the feet and recurrent ankle twisting, which raises the question to the possibility of more complications; one study concludes that having flat feet or high-arched feet has lower incidence of lower extremity injuries when compared to normal feet [27]. In contrast to another study, which concludes lack of evidence to support the relationship between the type of foot and the incidence of lower limb injuries [28]. Add more about 
complications: planter fasciitis is one of the most common. However, other studies show a positive correlation between foot type and injury, for example, one study concludes that runners with high or low arch structures are related to different injury patterns [29] and another found a positive correlation between foot type and knee pain but not ankle sprain [30]. When it comes to other complications like Medial Compartment Knee Osteoarthritis, a study concludes that pronated feet, in which flat feet are susceptible to, are associated with medial knee $\mathrm{OA}$, whereas high-arched feet are a protective factor [31]. As for lower back pain, a significant correlation was found between flat feet and an increase in the lumbar curvature whereas higharched feet are correlated with lumbar rectification in women complaining of low back pain [32].

\section{Conclusion}

As seen in our results, Flat foot is common in our community. Flatfoot can result in pain and disability if left uncorrected. As healthcare providers we should raise the level of awareness of the population that the incidence of the flat foot and its complications increase with obesity, which may decrease the quality of life. The authors recommended to establish a new method to diagnose flatfoot that gives us an accurate measure.

\section{Financial support and sponsorship}

Nil.

\section{Conflicts of Interest}

There are no Conflicts of interest.

\section{Reference}

1. Woźniacka R, Bac A, Matusik S, Szczygieł E, Ciszek E (2013) Body weight and the medial longitudinal foot arch: High-arched foot, a hidden problem? Eur J Pediatr 172(5): 683-691.

2. Mcpoil T, G Knecht H (1985) Biomechanics of the Foot in Walking: A Function Approach. J Orthop Sports Phys Ther 7(2): 69-72.

3. Pourghasem M, Kamali N, Farsi M, Soltanpour N (2016) Prevalence of flatfoot among school students and its relationship with BMI. Acta Orthop Traumatol Turc 50(5): 554-557.

4. Bluman EM, Title CI, Myerson MS (2007) Posterior Tibial Tendon Rupture: A Refined Classification System. 12(2): 233-249.

5. Abosala A, Tumia N, Anderson D (2003) Tibialis posterior tendon rupture in children. Injury 34(11): 866-867.

6. Menz HB, Fotoohabadi MR, Wee E, Spink MJ (2012) Visual categorisation of the arch index: A simplified measure of foot posture in older people. J Foot Ankle Res 5(1).

7. Murley GS, Menz HB, Landorf KB (2009) A protocol for classifying normal- and flat-arched foot posture for research studies using clinical and radiographic measurements. J Foot Ankle Res 2: 22.

8. Queen RM, Mall NA, Hardaker WM, Nunley JA (2007) Describing the Medial Longitudinal Arch Using Footprint Indices and a Clinical Grading System. Foot Ankle Int 28(4): 456-462.

9. Gutiérrez-Vilahú L, Massó-Ortigosa N, Costa-Tutusaus L, Guerra-Balic M (2015) Reliability and Validity of the Footprint Assessment Method Using Photoshop CS5 Software. 105(3): 226-232.
10. Clarke HH (1933) An Objective Method of Measuring the Height of the Longitudinal Arch in Foot Examinations. Res Quarterly Am Phys Educ Assoc 4(3): 99-107.

11. Jerzy T (2018) Physiotherapy and Health Activity. 32-37.

12. Shariff SM, Manaharan T, Shariff AA, Merican AF (2017) Evaluation of foot arch in adult women: Comparison between five different footprint parameters. Sains Malaysiana 46(10): 1839-1848.

13. Pita-Fernández S, González-Martín C, Seoane-Pillado T, López-Calviño B, et al. (2015) Validity of Footprint Analysis to Determine Flatfoot Using Clinical Diagnosis as the Gold Standard in a Random Sample Aged 40 Years and Older. J Epidemiol 25(2): 148-154.

14. Cavanagh PR, Rodgers MM (1987) The arch index: A useful measure from footprints. J Biomech. 20(5): 547-551.

15. Zuil-Escobar JC, Martínez-Cepa CB, Martín-Urrialde JA, Gómez-Conesa A (2016) Reliability and Accuracy of Static Parameters Obtained From Ink and Pressure Platform Footprints. J Manipulative Physiol Ther 39(7): 510-517.

16. Yashika Kalra, Aga Ammar Murthuza, Geetanjali BG, Varsha Mokhasi, Rajini T (2016) Study of Footprints to Determine the Incidence of Pes Planus In South Population Using Staheli's Plantar Arch Index. Int J Curr Res.

17. Gonzalez-Martin C, Pita-Fernandez S, Seoane-Pillado T, Lopez-Calviño B, Pertega-Diaz S, et al. (2017) Variability between Clarke's angle and Chippaux-Smirak index for the diagnosis of flat feet. Colomb medica Cali 48(1): 25-31.

18. Zuil-Escobar JC, Martínez-Cepa CB, Martín-Urrialde JA, Gómez-Conesa A (2018) Medial Longitudinal Arch: Accuracy, Reliability, and Correlation Between Navicular Drop Test and Footprint Parameters. J Manipulative Physiol Ther 41(8): 672-679.

19. Chougala A, Phanse V, Khanna E, Panda S (2015) Screening of Body Mass Index and Functional Flatfoot in Adult: An Observational Study. Int J Physiother Res 3(3): 1037-1078.

20. Pita-Fernandez S, Gonzalez-Martin C, Aalonso-Tajes F, Seoane-Pillado T, Pertega-Diaz S, et al. (2017) Flat foot in a random population and its impact on quality of life and functionality. J Clin Diagnostic Res 11(4): 22-27.

21. Tejashree Bhoir M, Anap DB, Diwate A (2014) Prevalence of flat foot among 18-25 years old physiotherapy students: cross sectional study. Indian J Basic Appl Med Res 3(4): 272-278.

22. Gay A, Culliford D, Leyland K, Arden NK, Bowen CJ (2014) Associations between body mass index and foot joint pain in middle-aged and older women: A longitudinal population-based cohort study. Arthritis Care and Research 66(12): 1873-1879.

23. Dufour AB, Losina E, Menz HB, LaValley MP, Hannan MT (2017) Obesity, foot pain and foot disorders in older men and women. Obes Res Clin Pract 11(4): 445-453.

24. Arnold JB, Causby R, Jones S (2010) The impact of increasing body mass on peak and mean plantar pressure in asymptomatic adult subjects during walking. Diabet Foot Ankle.

25. Song J, Kane R, Tango DN, Veur SSV, Furmato J, et al. (2015) Effects of weight loss on foot structure and function in obese adults: A pilot randomized controlled trial. Gait Posture 41(1): 86-92.

26. Walsh TP, Butterworth PA, Urquhart DM, Cicuttini FM, Landorf KB, et al. (2017) Increase in body weight over a two-year period is associated with an increase in midfoot pressure and foot pain. J Foot Ankle Res 10: 31 .

27. Tong JWK, Kong PW (2013) Association Between Foot Type and Lower Extremity Injuries: Systematic Literature Review With Meta-analysis. J Orthop Sport Phys Ther 43(10): 700-714. 
28. Chuter VH, Janse de Jonge XAK (2012) Proximal and distal contributions to lower extremity injury: A review of the literature. Gait and Posture 36(1): 7-15.

29. Williams DS, McClay IS, Hamill J (2001) Arch structure and injury patterns in runners. Clin Biomech 16(4): 341-347.

30. Dahle LK, Mueller M, Delitto A, Diamond JE (2013) Visual Assessment of Foot Type and Relationship of Foot Type to Lower Extremity Injury. J Orthop Sport Phys Ther 14(2): 70-74.
31. Abourazzak FE, Kadi N, Azzouzi H, Lazrak F, Najdi A, et al. (2014) A Positive Association Between Foot Posture Index and Medial Compartment Knee Osteoarthritis in Moroccan People 8: 96-99.

32. Borges C dos S, Fernandes LFRM, Bertoncello D (2013) Relationship between lumbar changes and modifications in the plantararch in women with low back pain. Acta Ortop Bras 21(3): 135-138.

\section{Your next submission with Juniper Publishers will reach you the below assets}

- Quality Editorial service

- Swift Peer Review

- Reprints availability

- E-prints Service

- Manuscript Podcast for convenient understanding

- Global attainment for your research

- Manuscript accessibility in different formats ( Pdf, E-pub, Full Text, Audio)

- Unceasing customer service

Track the below URL for one-step submission https://juniperpublishers.com/online-submission.php 